\title{
Spontaneous pneumomediastinum: A rare complication of anorexia nervosa
}

\author{
Pier Luigi Filosso, MD, ${ }^{\mathrm{a}}$ Domenica Garabello, MD, ${ }^{\mathrm{b}}$ Paraskevas Lyberis, MD, ${ }^{\mathrm{a}}$ Enrico Ruffini, MD, ${ }^{\mathrm{a}}$ and \\ Alberto Oliaro, $\mathrm{MD},{ }^{\mathrm{a}}$ Torino, Italy
}

Spontaneous pneumomediastinum (PM) usually results from alveolar wall rupture and must be distinguished from posttraumatic PM resulting from traumatic events (chest trauma, endobronchial or esophageal procedures with wall laceration, mechanical ventilation, or other invasive procedures).

Spontaneous PM is a rare entity in anorexia nervosa (AN): approximately 20 cases have been described in the literature. Vomiting (a common symptom in AN) is often the cause of $\mathrm{PM}$ in patients with AN.

We describe the case of spontaneous PM in a young anorexic woman in whom vomiting was not the cause of the PM.

\section{CLINICAL SUMMARY}

An 18-year-old nonsmoking anorexic woman with extreme malnutrition necessitating refeeding was referred to us because of subcutaneous air in the neck and thorax. Her height was $179 \mathrm{~cm}$ and weight $34 \mathrm{~kg}$.

She had anxiety while feeling an unusual crackling sensation in her neck and thorax, which rapidly developed when she was at home 1 day before her hospital admission; she had no dyspnea. No episodes of trauma, injury, vomiting, or coughing in the preceding days were reported by the patient or her parents, and no family history of emphysema, respiratory distress, or pneumothorax were evident.

Chest radiograph revealed subcutaneous emphysema in the neck and thorax; thoracic computed tomographic scan showed pneumomediastinum, without pneumothorax, extending from the neck to the diaphragm (Figure 1, $A$ and $B$ ). An esophageal gastric passage radiograph showed no abnormalities, and no signs of esophageal perforation were evident. Laryngopharyngoscopic findings were within normal

\footnotetext{
From the Department of Thoracic Surgery Via Genova, ${ }^{\mathrm{a}}$ University of Torino Italy, Torino, Italy, and Service of Radiology, ${ }^{\mathrm{b}}$ San Giovanni Battista Hospital Torino Italy, Torino, Italy.

Disclosures: None.

Received for publication March 21, 2008; revisions received April 3, 2008; accepted for publication April 13, 2008; available ahead of print May 28, 2009

Address for reprints: Pier Luigi Filosso, MD, University of Torino Italy, San Giovanni Battista Hospital, Department of Thoracic Surgery, Via Genova, 3, 10126 Torino, Italy (E-mail: pierluigifilosso@tiscali.it).

J Thorac Cardiovasc Surg 2010;139:e79-80

$0022-5223 / \$ 36.00$

Copyright (C) 2010 by The American Association for Thoracic Surgery

doi:10.1016/j.jtcvs.2008.04.037
}
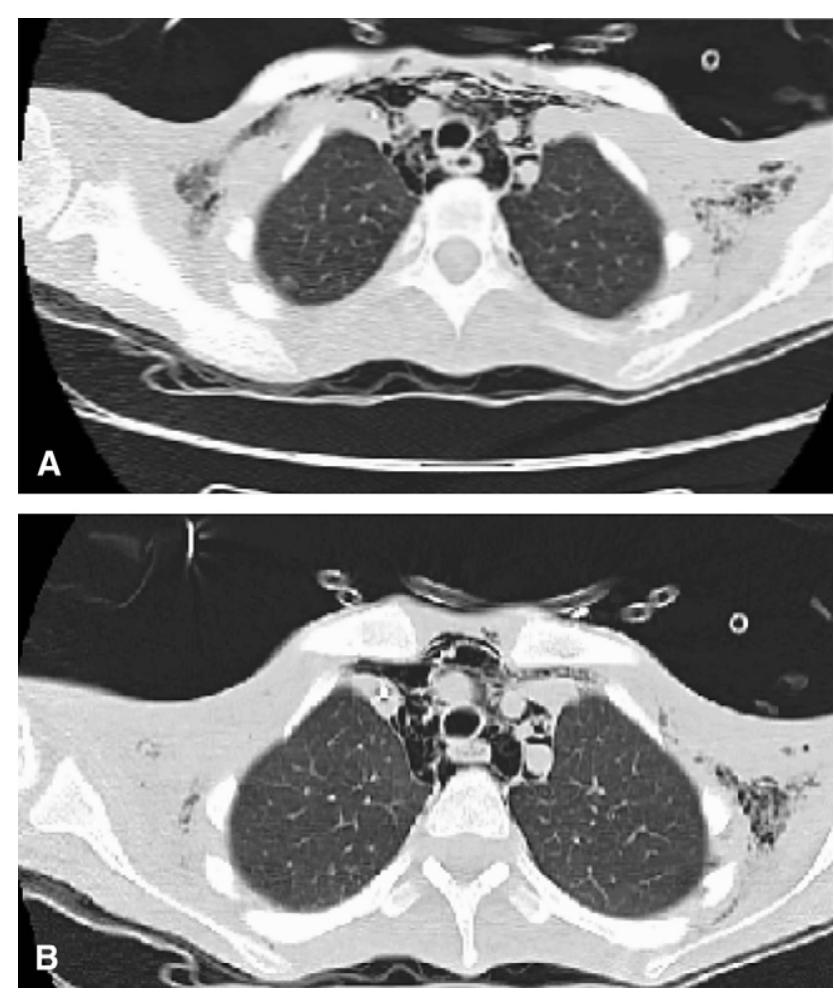

FIGURE 1. A and B, Thoracic computed tomographic scans of the patient. Diffuse subcutaneous emphysema, from the neck to the thorax, and pneumomediastinum are evident.

limits, too, without signs of mucosal lesions or submucosal swelling.

No surgical procedures were done: her condition was monitored by radiologic surveillance only. The PM disappeared within 2 weeks, and the patient was referred to an eating disorder clinic to manage the AN.

\section{DISCUSSION}

Spontaneous PM is an uncommon and generally benign entity developing in the absence of traumatic or iatrogenic events. Usually, respiratory maneuvers with high intrathoracic pressures (Valsalva maneuver, coughing, energic crying, or vomiting) have been implicated in its development. The intra-alveolar pressure increase causes alveolar rupture and the escape of air into the mediastinal space. Spontaneous PM rarely requires surgical drainage inasmuch as it usually resolves spontaneously. 
Clinical symptoms are sudden chest pain, dyspnea, and, less commonly, dysphagia and hoarseness. Physically, subcutaneous air and a typical crunching sound are present.

When chest pain and dyspnea are present, anxiety and panic attack are frequent. Panic disorders are often observed in anorexic patients: when chest pain and/or dyspnea or dysphagia appear, spontaneous PM should be considered. ${ }^{1}$

At present, 20 cases of spontaneous PM have been described in the literature. ${ }^{2-4}$

PM in anorexic patients is sometimes produced by selfinduced vomiting. ${ }^{3}$ Our patient had no history of vomiting, and the thorough diagnostic procedures (thoracic computed tomographic scan, esophageal radiologic evaluation, and laryngopharyngoscopy) showed no signs of esophageal or upper airway laceration.

The pathophysiologic mechanism of PM in our patient can be explained by an alveolar wall rupture, with consequent air leak into the mediastinum. The air was interestingly confined to the mediastinum only: no signs of pneumothorax were evident.

PM is sometimes observed in AN: self-induced vomiting causing an esophageal laceration is frequently the cause of $\mathrm{PM}$ in these patients.

Anorexic patients with severe malnutrition are at high risk for PM or pneumothorax. ${ }^{4}$
Animal studies reveal that calorie restriction results in an important loss of alveoli and a fall in gas-exchange tissue and thinner alveolar walls. ${ }^{5}$ The organism sacrifices the nonessential structures for gluconeogenesis to provide glucose for the brain and proteins for the muscles. Because the oxygen consumption falls during calorie restriction, some lung tissue is sacrificed. With thinner alveolar walls and the loss of alveoli, malnourished anorexic patients are at risk of alveolar wall rupture.

In conclusion, we can suppose that severe malnutrition, causing weakness of the alveolar wall and thinning of the connective tissue, can explain the occurrence of the PM in our patient.

\section{References}

1. Karim A, Ahmed S, Rossoff L. Pneumomediastinum simulating a panic attack in a patient with anorexia nervosa. Int J Eat Dis. 2002;33:104-7.

2. Overby KJ, Litt IF. Mediastinal emphysema in an adolescent with anorexia nervosa and self-induced emesis. Pediatrics. 1988;81:134-6.

3. Folsom T, Realmuto MD. Pneumomediastinum in an adolescent female with anorexia nervosa. Int J Eat Dis. 2006;3:67-70.

4. van Veelen I, Hogerman PHG, van Elburg A, Nielsen-Abbring FW, Heggelman BGF, Mahieu HF. Pneumomediastinum: a rare complication of anorexia nervosa in children and adolescents. A case study and review of the literature. Eur J Pediatr. 2008;167:171-4.

5. Massaro D, Massaro GD, Baras A, Hoffman EP, Clerch LB. Calorie-related rapid onset of alveolar loss, regeneration, and changes in mouse lung gene expression. Am J Physiol Lung Cell Mol Physiol. 2004;286:L896-906.

\title{
Transcranial Doppler ultrasonography: A reliable method of monitoring pulsatile flow during cardiopulmonary bypass in infants and young children
}

\author{
Ashley Rogerson, BS, ${ }^{\mathrm{a}}$ Yulong Guan, MD, ${ }^{\mathrm{a}}$ Stephen J. Kimatian, MD, ${ }^{\mathrm{b}}$ Allen Kunselman, MA, ${ }^{\mathrm{a}}$ \\ J. Brian Clark, MD, ${ }^{\mathrm{a}, \mathrm{b}}$ John L. Myers, MD, ${ }^{\mathrm{a}, \mathrm{b}}$ and Akif Ündar, PhD, ${ }^{\mathrm{a}, \mathrm{c}, \mathrm{d}}$ Hershey, Pa
}

\footnotetext{
From the Pediatric Cardiac Research Laboratories, Departments of Pediatrics ${ }^{\mathrm{a}}$ Pediatric Anesthesiology, ${ }^{\mathrm{b}}$ Surgery, ${ }^{\mathrm{c}}$ and Bioengineering, ${ }^{\mathrm{d}}$ Penn State Milton S. Hershey Medical Center, Penn State College of Medicine, Penn State Hershey Children's Hospital, Hershey, Pa.

Disclosures: None.

This research was supported by the Children's Miracle Network.

Received for publication Dec 23, 2008; revisions received Feb 9, 2009; accepted for publication Feb 16, 2009; available ahead of print June 15, 2009.

Address for reprints: Akif Ündar, PhD, Associate Professor of Pediatrics, Surgery, and Bioengineering, Penn State College of Medicine, Department of Pediatrics-H085, 500 University Dr, PO Box 850, Hershey, PA 17033-0850 (E-mail: aundar@psu. edu).

J Thorac Cardiovasc Surg 2010;139:e80-2

$0022-5223 / \$ 36.00$

Copyright (c) 2010 by The American Association for Thoracic Surgery doi:10.1016/j.jtcvs.2009.02.053
}

With a reported incidence ranging from $2 \%$ to $25 \%$, neurologic morbidity remains a leading complication in infants and children undergoing cardiac operations requiring the use of cardiopulmonary bypass (CPB). ${ }^{1}$ Maintaining optimal cerebral perfusion and hemodynamics during $\mathrm{CPB}$ procedures should be the goal to prevent long-term neurologic complications after pediatric open cardiac operations.

Pulsatile flow during CPB generates significantly more hemodynamic energy levels than does nonpulsatile flow at the same mean arterial pressures and pump flow rates in neonates and infants. ${ }^{2,3}$ Extra energy generated by pulsatile flow may maintain better cerebral blood flow. ${ }^{3}$ We focused on Gosling's pulsatility index (PI) inasmuch as it is accepted as a reliable measure of pulsatility and available on all 